Jasmina Markič

UDK 811.134.2’367.4:82García Márquez G.

Facultad de Filosofía

DOI: 10.4312/vestnik.7.109-119

Universidad de Ljubljana

jasmina.markic@ff.uni-lj.si

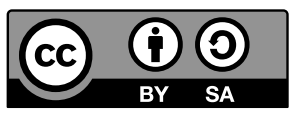

\title{
LA PERÍFRASIS VERBAL IR A + INFINITIVO EN LAS OBRAS NARRATIVAS DE GABRIEL GARCÍA MÁRQUEZ'
}

\section{ACERCA DEL CONCEPTO DE PERÍFRASIS VERBAL}

Las perífrasis verbales se suelen definir de acuerdo con los criterios sintáctico-semánticos como combinación de dos elementos verbales, un verbo auxiliar flexionado y un verbo auxiliado o principal en forma no flexionada (infinitivo, gerundio o participio) que forman una unidad sintáctico-semántica ${ }^{2}$, es decir, constituyen un solo núcleo del predicado e indican diferentes valores aspectuales, modales, contextuales y, en menor medida, temporales. Los dos verbos se vinculan mediante unión directa ( $\sin$ nexos) en las perífrasis verbales de gerundio, de participio y algunas de infinitivo o indirecta (con nexos - preposiciones, conjunciones, frases conjuntivas) en el caso de las perífrasis verbales de infinitivo (ir a + infinitivo, tener que + infinitivo, estar a punto de + infinitivo). Las perífrasis verbales funcionan como una sola unidad verbal, es decir, su significado propio proviene de la fusión de ambos elementos constitutivos. No se trata simplemente de la suma de los significados de sus elementos, estos no pueden separarse el uno del otro, ni pueden tener relaciones sintácticas propias ${ }^{3}$.

\section{ACERCA DEL CONCEPTO DE FUTURIDAD}

Se suele afirmar que el valor temporal del futuro es uno de los valores primordiales o básicos del paradigma verbal futuro simple o imperfecto. Sin embargo, es sabido que no es así ya que los paradigmas verbales futuros y condicionales son propensos a modalizarse indicando modalidad epistémica o deóntica. La modalización del futuro es un fenómeno tan

1 La investigación que subyace al trabajo se enmarca en el Proyecto FFI2012-33807, del Ministerio de Economía y Competitividad, del Gobierno de España, y en el programa de investigación del Instituto de Investigación Científica de la Facultad de Filosofía y Letras de la Universidad de Ljubljana, Eslovenia.

2 Existen también unas construcciones verbales, denominadas perífrasis verbales copulativas, formadas de dos verbos conjugados relacionados con la conjunción copulativa $y$, cuyos significado y función se asemejan a las perífrasis verbales. Son primordialmente expresiones coloquiales y narrativas. La acción se presenta como no dividida, intensa, brusca, rápida con matices de sorpresa, de algo inesperado y repentino (Va y me dice...). El esloveno conoce una estructura verbal semejante (Gre in mi reče...).

3 Cfr. Gómez Torrego (1999), Yllera (1999), García Fernández (2006). 
importante, por su difusión y frecuencia, que algunos lingüistas dudan de que el futuro indique básicamente temporalidad (Reyes 1990: 110). Según Fernández Ramírez (1986: 284) el futuro es «un tiempo verbal cargado de matices significativos y valores modales que exceden en mucho de la simple referencia a un momento o período posterior al que se describe, o a aquel en que se habla. Estos valores pueden incluso anular la futuridad misma».

El futuro simple o imperfecto denominado también futuro absoluto se formó por aglutinación del infinitivo con el presente del verbo haber, es decir, de una perífrasis verbal. Los futuros latinos en -bo y en -am (AMABO, AUDIAM) desaparecieron y fueron sustituidos, ya en latín vulgar, por el infinitivo seguido del presente de HABERE: CANTARE + HA$\mathrm{BEO}>$ cantar + he $=$ cantaré. En la Edad Media los dos componentes se escribían a menudo separados ${ }^{4}$. Asimismo el condicional simple se formó por aglutinación del infinitivo con el imperfecto de indicativo contracto del auxiliar HABERE y el infinitivo (CANTARE + HABEBAM). Era por lo tanto una perífrasis verbal que se usaba en su origen para expresar la obligación presente 5 .

El futuro, en cuanto tiempo de aquello que aún no es, implica no sólo la distancia temporal prospectiva del punto de referencia considerado, sino también una necesaria hipótesis acerca de la realización de la acción verbal designada: los tiempos verbales futuros, desde el punto de vista ontológico, no se refieren en rigor a hechos sino a la posibilidad más o menos segura de su ocurrencia. (Cartagena 2000: 2957)

En la expresión del futuro se nota una tendencia histórica en español y en las lenguas romances en general ${ }^{6}$ a sustituir las formas sintéticas por las analíticas. Una vez que la analítica, que en este caso procede de una perífrasis verbal modal obligativa (CANTARE HABEO > cantaré) se transforma en sintética, esta comienza a ser sustituida por otra forma analítica (el actual futuro simple está siendo reemplazado por la perífrasis verbal ir a + infinitivo). Es lo que afirma también Fleischman (1982) en su estudio diacrónico del futuro en las lenguas romances. La autora (Fleischman 1982: 103-104) considera que se trata de una alternancia cíclica entre las formas sintéticas y analíticas ya que el hablante concibe el futuro desde su presente como una proyección de su querer, su intención o su temor (Montes Giraldo 1962: 528) y presenta hasta un ejemplo de fusión de la perífrasis verbal ir a + infinitivo en una forma sintética en el español de Panamá vadormir (Fleischman 1982: 104).

En el español de América existe una tendencia general a sustituir las formas sintéticas indicadoras de la posterioridad (futuro simple y condicional simple) por la forma analítica ir a + infinitivo con el auxiliar en presente o imperfecto respectivamente. La forma en -ré es

4 «E dezirte he que nunca rey fue en España que corona se pusiese en la cabeça en quanto sus enemigos que no havía duda que no fuese bueno, e con todo esto no duravan mucho en ella (Corral, Don Rodrigo)», ejemplo de NGLE (2009: 1769).

5 Cfr. Markič 2010.

6 Cfr. Müller Pograjc 2014. 
reemplazada por la perífrasis verbal ir a + infinitivo con el auxiliar en presente o por el presente de indicativo, incluso por otras perífrasis verbales como estar + gerundio en la costas peruanas (Donadío Copello 2005: 193) o la perífrasis verbal haber de + infinitivo. En Colombia, en la lengua hablada, el futuro simple con su valor temporal prospectivo está prácticamente desaparecido (Montes Giraldo 1962: 527), pero se sigue usando en sus valores modales, sobre todo los de posibilidad y probabilidad (1), de concesión (2) o de cortesía (3). A veces con matices de temporalidad futura o sin cualquier indicación de la futuridad. La forma de futuro simple con el valor de futuro aparece, en el español de Colombia, en la lengua escrita que tiende a respetar la norma académica pero aún en esos usos suele aparecer algún matiz modal: lo temporal futuro va combinado con los valores modales.

(1) Camine, métase un traguito, señora, o cómase un casaíto, que usté hasta tendrá mucha hambre. (Arango, Obras, 112, citado por Montes Giraldo 1963: 533)

(2) -Pues no tendré banco, pero sí llevé un gran surtido de mercancías, lo realicé por allá y traje muchos artículos para vender aquí. (Arango, Obras, 90, citado por Montes Giraldo 1963: 534)

(3) Su Mercé me dispensará; pero a yo me ocupa la vergüenza y no me arresto a recebile. (LMarq., 283, citado por Montes Giraldo 1963: 534)

El ejemplo (4) es una combinación de la perífrasis verbal ir a + infinitivo con valor temporal de futuro y modal de intención y la perífrasis verbal obligativa tener que + infinitivo en futuro simple con valor de obligación futura. En la oración (5) la futuridad se indica con la perífrasis verbal haber de + infinitivo y el futuro simple, usados, en este caso, como una sentencia bíblica.

(4) -Y ahora, señoras y señores, vamos a mostrar la prueba terrible de la mujer que tendrá que ser decapitada todas las noches a esta hora durante cincuenta años, como castigo por haber visto lo que no debía. (García Márquez 1986: 33)

(5) -Si has de parir iguanas, criaremos iguanas - dijo-. Pero no habrá más muertos en este pueblo por culpa tuya. (García Márquez 1986: 25)

\section{LA PERÍFRASIS VERBAL IR A + INFINITIVO}

Se trata de una construcción formada por el verbo ir y el infinitivo de otro verbo denominado principal, vinculados mediante la unión indirecta con la preposición $a$ en su uso actual. Antiguamente prevalecía la forma sin nexo y la construcción ir + infinitivo aún estaba en proceso de gramaticalización. En el Cantar de Mio Cid aparece sin preposición con la idea de movimiento para hacer algo e indicar la intención de hacer algo (Menéndez Pidal 
en Montes (1962: 543)7 . Según Zieliński (2014: 124) se trata de dos construcciones paralelas cuyos significados figurativos son casi idénticos, «ambas parten del mismo esquema de movimiento delimitado, con objetivo de realizar algún evento». Hoy en día es la perífrasis verbal más usada en español. El verbo auxiliar ir (siempre en la forma no pronominal) está fuertemente gramaticalizado, es decir, en la perífrasis verbal pierde su valor léxico de verbo de movimiento, cuando se encuentra como parte constituyente de una perífrasis verbal.

Numerosos estudios han sido dedicados en el pasado a esta estructura perifrástica en las que las definiciones oscilan entre el valor aspectual incoativo y el temporal de futuro o posterioridad. Así, por ejemplo, Gili Gaya (1961: 107-108) destaca su valor incoativo, Roca Pons (1958: 72-73) considera que la perífrasis expresa un futuro próximo o lejano, Seco (1975: 189) le atribuye valor temporal, mientras que Hernández Alonso (1986: 381) le atribuye solo valor aspectual incoativo. Por otra parte Bauhr (1989: 43-55) opina que ir a + infinitivo no indica valores aspectuales sino solo el valor temporal de posterioridad, por lo que clasifica dicha perífrasis verbal en la categoría del tiempo. Estas oscilaciones acerca de los valores aspectuales y temporales de la perífrasis ir a + infinitivo reflejan que en la perífrasis aparecen ambos valores además de los valores modales que se desprenden de ellos. Actualmente la NGLE destaca que «los usos de la perífrasis ir a + infinitivo corresponden en general a la dimensión temporal ( $\mathrm{Va}$ a llover) hasta el punto de que alterna muy a menudo con el futuro en español contemporáneo o se prefiere a él en muchas zonas» (NGLE, Sintaxis II 2009: 2116). Gómez Torrego (1999: 3365) la incluye dentro del grupo aspectual porque opina que «el aspecto, junto con el valor temporal de futuridad, son sus valores dominantes» pero afirma que también muestra los rasgos modales deónticos y epistémicos. El diccionario de perifrasis verbales la define como perífrasis aspectual progresiva (García Fernández 2006: 177). Dos son, por tanto, los valores primordiales, el temporal y el aspectual, mientras que los usos modales parecen desprenderse de estos. Se trata de valores modales fuertemente ligados al contexto: epistémicos (de probabilidad), deónticos (de intención) y otros matices ${ }^{8}$.

\section{EJEMPLOS DE USO}

La perífrasis verbal ir a + infinitivo aparece con todos los valores arriba mencionados en los textos narrativos (novelas y relatos) analizados del escritor colombiano Gabriel García Márquez.

7 «Sea como fuere, la construcción con el valor final aparece desde los primeros textos del castellano con o sin elemento de enlace $a(<\mathrm{AD})$, que marca explícitamente la finalidad a través de la metáfora FINALIDAD ES DESTINO, basada en la metonimia DESTINO POR FIN DE CAMINO [...] se desprende que durante los primeros siglos la variante con el nexo escasea y su empleo va incrementándose con el paso del tiempo.» (Zieliński 2014: 123). 8 Cfr. García Fernández (2006: 177-182). 
4.1 En cuanto a su valor aspectual ${ }^{9}$ la perífrasis verbal focaliza el momento inmediatamente anterior al comienzo del evento. Normalmente, en este uso, la perífrasis no puede sustituirse por el futuro imperfecto porque es incompatible con los complementos adverbiales que suelen acompañarla y denotan un momento simultáneo al tiempo de referencia.

(6) El niño, perplejo en la puerta, dijo: «Se va a caer.» La olla estaba bien puesta en el centro de la mesa, pero tan pronto como el niño hizo el anuncio, inició un movimiento irrevocable hacia el borde, como impulsada por un dinamismo interior, y se despedazó en el suelo. (García Márquez 1986: 19-20)

(7) Victoria Guzmán estaba vigilando la cafetera en el fogón cuando él pasó por la cocina hacia el interior de la casa.

-Blanco- lo llamó ya va a estar el café. (García Márquez 1981: 90)

El valor de inminencia también aparece en la esfera del pasado con el auxiliar en imperfecto de indicativo. En el uso estrictamente aspectual el auxiliar no va nunca en pretérito perfecto simple ni en pretérito perfecto compuesto ${ }^{10}$.

(8) Iban a ser las siete cuando atracamos en un pantano pestilente a poca distancia de la población de Ciénaga. (García Márquez 2002: 20)

En los ejemplos (9) y (10) prevalece el valor de inevitabilidad de las acciones que están a punto de realizarse y se realizan.

(9) Ibrahim Nasar lo compró a cualquier precio para poner una tienda de importación que nunca puso, y sólo cuando se iba a casar lo convirtió en una casa para vivir. (García Márquez 1981: 19)

(10) Apenas iban a ser las siete y ya entraba un sol dorado por las ventanas.

(García Márquez 1981: 137)

Las acciones que estaban a punto de realizarse pueden no llevarse a cabo. Con el auxiliar en pretérito de imperfecto se da el valor de conato, como variante de lo intencional (Gómez Torrego 1999: 3369).

\footnotetext{
9 En este estudio se considera el aspecto verbal en su sentido amplio, es decir, las características del desarrollo de la acción verbal en el tiempo (acciones momentáneas, reiterativas, habituales, resultativas, etc.), lo que frecuentemente se denomina Aktionsart; el tipo de la acción (estado, no estado, acciones télicas y atélicas); las partes de la acción (incoativa, intermedia - durativa, terminativa), lo que normalmente se denomina la fase de la acción; el aspecto en el sentido estrecho, lo que normalmente se denomina aspecto verbal y expresa cómo el hablante ve la acción, desde qué punto de vista o perspectiva la observa, es decir, abarca la acción en su totalidad (perspectiva global) o abarca la acción parcialmente y señala una parte de la acción sin interesarle el inicio y el final (perspectiva cursiva).
}

10 Cfr. García Fernández (2006: 180). 
(11) Santiago Nasar la agarró por la muñeca cuando ella iba a recibirle el tazón vacío. (García Márquez 1981: 17)

(12) El padre Antonio Isabel del Santísimo Sacramento del Altar acababa de subir al púlpito. Iba a iniciar el sermón cuando vio entrar a un muchacho con el sombrero puesto.

(García Márquez 1985: 70)

En la primera oración de la novela Crónica de una muerte anunciada (13), en la perífrasis verbal con el verbo auxiliar en imperfecto (iban a matar), los valores temporales (posterioridad), aspectuales (inminencia de la acción) y modales (intención) se funden para concederle un matiz de anticipación y previsión. El narrador anticipa la acción pero deja al lector en suspense ya que no se expresa explícitamente si la acción llega a su final o no dejando abiertas las dos posibilidades.

(13) El día en que lo iban a matar, Santiago Nasar se levantó a las 5:30 de la mañana para esperar el buque en que llegaba el obispo. (García Márquez 1981: 9)

4.2 Por lo que respecta al valor temporal la perífrasis presenta usos con valor de futuro (o futuro de pasado) cuando el auxiliar se encuentra en presente de indicativo (o en imperfecto de indicativo). Este uso de la perífrasis en lugar del futuro imperfecto prevalece en el español de Colombia, el futuro imperfecto en su valor temporal de futuridad es casi inexistente. En el uso estrictamente temporal el auxiliar puede ir solamente en presente o en imperfecto de indicativo ${ }^{11}$ como se presenta en los siguientes ejemplos:

(14) Y como él no entendió lo que ella quería decirle, se lo explicó por letra:

-Vas a tener un hijo. (García Márquez 1986: 32)

(15) No es justo que todo el mundo sepa que le van a matar el hijo, y que ella sea la única que no lo sabe. (García Márquez 1981: 34)

(16) A Usted van a estar esperándola una cantidad de periodistas - dijo el hombre-. (García Márquez 1996: 191)

(17) «Prométame que no los va a leer nadie», -dijo. (García Márquez 1986:105)

(18) Esto es una operación militar y a ustedes no les va a pasar nada. (García Márquez 1996: 17)

(19) - ¿Puedo decirle a tu papá que vas a decirle que sí?

-No -le repliqué de un tajo-. Eso no. (García Márquez 2002: 18)

11 «El valor temporal de futuridad puede darse desprovisto del significado aspectual de 'estar a punto de'. Ese futuro suele ser inmediato en la realidad física o en la realidad psicológica, subjetiva, del hablante. Con la perífrasis, la futuridad se ve más próxima e, incluso, más segura en la apreciación del hablante.» (Gómez Torrego 1999: 3368) 
(20) -Empecemos a arreglar cómo es que voy a entregarme.

En realidad, Escobar sabía ya cómo iba a entregarse pero tal vez quería hacer un repaso completo con un hombre en el cual tenía depositada entonces su confianza. (García Márquez 1996: 308)

(21) -Esta piel cuesta un dineral -me dijo sin dramatismos-, pero te aconsejo que no la vendas mientras no sientas que te vas a morir de hambre. (García Márquez 2002: 194)

(22) La realidad es que no entendía por qué debía sacrificar ingenio y tiempo en materias que no me conmovían y por lo mismo no iban a servirme de nada en una vida que no era mía. (García Márquez 2002: 264)

(23) Mejor dicho: los años volaban y no tenía ni la mínima idea de lo que iba a hacer de mi vida [...]. (García Márquez 2002: 265)

4.3 El valor de futuro o de posterioridad en el pasado va acompañado, en ocasiones, de valores modales. En los ejemplos que siguen destaca el valor modal de intención:

(24) Vamos a matar a Santiago Nasar -dijo. (García Márquez 1981: 71)

(25) Vamos a matar a Santiago Nasar -le dijo. (García Márquez 1981: 92)

(26) «Lo que hay que hacer con esos chapetones de porra es sacarlos a patadas de Venezuela», dijo. «Y le juro que lo voy a hacer». (García Márquez 1989: 138)

(27) De todos modos voy a renunciar a esta joda -le dijo a Villamizar con su lengua florida. -Estamos aquí de puro pendejos. (García Márquez 1996: 34)

(28) -Dígale que lo único que quiero en la vida es ser escritor, y que lo voy a ser. (García Márquez 2002: 28)

(29) -No sé por qué insiste tanto, si usted sabe muy bien que no voy a rendirme -le dije. (García Márquez 2002: 28)

En contextos coloquiales exclamativos o interrogativos la perífrasis ir a + infinitivo cobra otros valores modales. En el ejemplo (30) al valor temporal de futuro se le añade un matiz de sorpresa.

(30) ¡Imagínese -les dijo-: qué va a decir el obispo si los encuentra en ese estado! (García Márquez 1981: 77)

En entornos coloquiales ir a + infinitivo sirve para indicar estados anímicos (sorpresa, reproche, advertencia, amenaza) que corresponden a actos ilocutivos concretos (Gómez Torrego 1999: 3370).

(31) - ¡No haga preguntas! -le respondió uno de ellos con un gruñido áspero-- ¡Qué voy saber de eso! (García Márquez 1996: 187). 
(32) Pero ni más faltaba que fuera a renunciar a su infinita capacidad de ilusión en el momento en que más le convenía. (García Márquez 1989: 144)

(33) -Si tienes ganas de hacer algo, hazlo ahora - dijo la mujer-. Después, aunque te estés muriendo de sed no tomes agua en ninguna parte. Sobre todo no vayas a llorar. (García Márquez 1985: 8)

(34) Ay, Tobías -exclamó-. Ay, Tobías, por el amor de Dios, no vayas a empezar ahora otra vez con estas cosas. (García Márquez 1986: 32)

A veces, con el auxiliar en primera persona del plural, el valor de futuridad desaparece o pasa a segundo plano predominando un valor exhortativo. La forma vamos a ver (35) ya fijada como una locución, con frecuencia aparece en su forma abreviada a ver (36) sin el verbo auxiliar.

(35) -Vamos a ver quién se cansa primero - dijo la abuela-, ellos o yo. (García Márquez 1986: 86)

(36) «A ver si ahora sí creen que nos fuimos», dijo. (García Márquez 1989: 93).

\section{NOTAS CONCLUSIVAS}

El análisis de la perífrasis verbal ir a + infinitivo que indica valores aspectuales, temporales y modales en las obras de Gabriel García Márquez demuestra que los valores dominantes son el temporal de futuridad y el aspectual de inminencia. En su papel de indicador de valores de futuridad reemplaza el paradigma verbal futuro imperfecto, no solo en el lenguaje oral (Montes Giraldo 1985: 169-193) sino también en el escrito, como se desprende de los ejemplos citados. Este uso de la perífrasis corresponde a la tendencia de la expresión de carácter venidero de las formas analíticas en las lenguas romances en general y en español en particular (Fleischman 1982, Montes Giraldo 1985, Zieliński 2014). Al valor de futuro se le añaden valores modales, especialmente el deóntico. Además, la perífrasis verbal cobra valores contextuales con matices de sorpresa, advertencia, amenaza, temor. La perífrasis verbal ir a + infinitivo tiene una gran riqueza de matices semánticos que se prestan a diferentes usos estilísticos como se puede comprobar al analizar los textos narrativos del gran escritor colombiano.

\section{REFERENCIAS BIBLIOGRÁFICAS}

BAUHR, Gerhard (1989) El futuro en -ré e ir a + infinitivo en español peninsular moderno. Gotemburgo: Romanica Gothoburgensia XXXIX. 
CARTAGENA, Nelson (2000) Los tiempos compuestos. Bosque, Ignacio y Demonte, Violeta (eds.) Gramática descriptiva de la lengua española. Madrid: Espasa, 2935-2975. DONADÍO COPELLO, María (2005) Morfosintaxis del español americano: La variación morfosintáctica. ARÁUS PUENTE, Cándido (ed.) Manual de lingüística hispanoamericana, Tomo II. Bogotá: ICC, 193-223.

GARCÍA FERNÁNDEZ, Luis (dir.) (2006) Diccionario de perifrasis verbales, Madrid: Gredos.

GÓMEZ TORREGO, Leonardo (1999) Los verbos auxiliares. Las perífrasis verbales de infinitivo. BOSQUE, Ignacio, DEMONTE, Violeta (dirs.), Gramática descriptiva de la lengua española, Madrid: Espasa, 3323-3389.

GILI GAYA, Samuel (1961) Curso Superior de sintaxis española. Barcelona: Vox Bibliograf.

GÓMEZ MANZANO, Pilar (1992) Perifrasis verbales con infinitivo. Madrid: UNED.

FERNÁNDEZ RAMÍREZ, Salvador (1986) Gramática española, 4. El verbo y la oración. Madrid: Arco/Libros.

FLEISCHMAN, Suzanne (1982) The Future in Thought and Language. Diachronic Evidence from Romance. Cambridge: Cambridge University Press.

HERNÁNDEZ ALONSO, César (1986) Gramática funcional del español. Madrid: Gredos.

MARKIČ, Jasmina (1998) Los valores aspectuales en el español moderno de América en las obras del escritor colombiano Gabriel García Márquez. Verba Hispanica, 7, 47-88.

MARKIČ, Jasmina (2010) El verbo en español. Ljubljana: Filozofska fakulteta.

MONTES GIRALDO, José Joaquín (1962) Sobre la categoría de futuro en español de Colombia. Thesaurus, XVII/3. Bogotá: ICC, 384-403.

MONTES GIRALDO, José Joaquín (1963) Sobre las perífrasis con ir en el español de Colombia. Thesaurus, XVIII/2. Bogotá: ICC. 384-403.

MONTES GIRALDO, José Joaquín (1985) Estudios sobre el español de Colombia. Bogotá: ICC.

MÜLLER POGRAJC, Blažka (2014) Cantaré e cantaría / cantarei e cantaria: usos retos e deslocados. Verba Hispanica, 22, 59-67.

REAL ACADEMIA ESPAÑOLA (2009) Nueva gramática de la lengua española (NGLE). Madrid: Espasa.

REYES, Graciela (1990) La pragmática lingüística. El estudio del uso del lenguaje. Barcelona: Montesinos.

ROCA PONS, Josep (1958) Estudios sobre perifrasis verbales del español. RFE, Anejo LXVII. Madrid: CSIC.

ZIELIŃSKI, Andrzej (2014) Las perifrasis de los verbos de movimiento en español medieval y clásico. Krakow: Wydawnictwo Uniwersytetu Jagiellońskiego. 


\section{TEXTOS CITADOS}

GARCÍA MÁRQUEZ, Gabriel (1986) Cien años de soledad. Bogotá: Editorial La Oveja Negra.

GARCÍA MÁRQUEZ, Gabriel (1981) Crónica de una muerte anunciada. Bogotá: Editorial La Oveja Negra.

GARCÍA MÁRQUEZ, Gabriel (1989) El general en su laberinto. Madrid: Mondadori.

GARCÍA MÁRQUEZ, Gabriel (1986') La increíble y triste historia de la cándida Eréndira y de su abuela desalmada. Bogotá: Editorial La Oveja Negra.

GARCÍA MÁRQUEZ, Gabriel (1985) Los funerales de la Mamá Grande. Bogotá: Editorial La Oveja Negra.

GARCÍA MÁRQUEZ, Gabriel (1996) Noticia de un secuestro. Barcelona: Grijalbo Mondadori.

GARCÍA MÁRQUEZ, Gabriel (2002) Vivir para contarla. Barcelona: Mondadori

\section{POVZETEK}

\section{Glagolska perifraza ir a + nedoločnik v pripovednih delih Gabriela Garcíe Márqueza}

Članek obravnava eno najpogosteje rabljenih glagolskih perifraz v španščini ir $a+$ nedoločnik in njene aspektualne in časovne vrednosti, ki pa ne nastopajo vedno ločeno, temveč se pojavljajo skupaj in pridobivajo modalne vrednosti. Vlogo označevalca prihodnjega časa vedno bolj prevzema glagolska perifraza ir $a+$ nedoločnik, ki je v ameriški (v tem primeru v kolumbijski) španščini, v pogovornem in celo pisnem jeziku, skoraj popolnoma izpodrinila enostavno glagolsko obliko. Članek se osredotoča na analizo ir $a+$ nedoločnik v pripovednih delih Gabriela Garcíe Márqueza. Razen časovne vrednosti izstopa tudi inhoativna aspektualna vrednost dejanja tik pred uresničitvijo in druge modalne vrednosti, ki vse skupaj prispevajo k posebnim slogovnim učinkom v analiziranih pripovednih besedilih. Večno nihanje med modalnostjo in časovnostjo v španskem jeziku je čutiti tudi v tej glagolski perifrazi. Vprašanje izražanja prihodnosti nasploh je problematično, ker gre za čas, ki ga še ni, oz. šele prihaja. Govorec/pripovedovalec izraža predvidevanje, namen, obveznost, željo, načrt.

Ključne besede: glagolska perifraza, časovnost, aspektualnost, modalnost, prihodnjik, ir $a+$ nedoločnik 


\section{ABSTRACT \\ The Verbal Periphrasis ir a + Infinitive in the Narrative Texts by Gabriel García Márquez}

This article deals with ir $a+$ infinitive, one of the most frequent verbal periphrases in Spanish with temporal, aspectual and modal values. It presents the analysis of narrative texts written by the Colombian writer Gabriel García Márquez and emphasizes the expression of aspectual values of imminence of the event and the expression of future with the auxiliary verb in present replacing the simple future tense in Colombian Spanish corroborating, thus, the fact that in contemporary American Spanish the expression of futurity is in the process of transfer from a synthetic to an analytic form. However, these aspectual and temporal values are not always alone, frequently they merge with other mainly modal values which confer to this periphrasis additional expressive and stylistic uses.

Key words: verbal periphrasis, temporality, aspectuality, modality, future, ir $a+$ infinitive

\section{RESUMEN}

\section{La perífrasis verbal ir a + infinitivo en las obras narrativas de Gabriel García Márquez}

El artículo analiza el uso de la perífrasis verbal ir a + infinitivo en sus usos temporales, aspectuales y modales a los que se les añaden numerosos matices contextuales. El análisis se centra en el uso de la perífrasis verbal en el español de Colombia con ejemplos de las obras narrativas de Gabriel García Márquez. Destaca el uso de la perífrasis verbal en su valor aspectual de inminencia de la acción y en su valor temporal de futuro con el verbo auxiliar en presente de indicativo o futuro del pasado con el auxiliar en imperfecto de indicativo frente a la forma del paradigma verbal futuro simple o condicional simple respectivamente, hecho dominante en el español de Colombia. También se comprueba que los valores temporales y aspectuales no aparecen siempre aisladamente sino que de ellos se desprenden numerosos valores modales formando de esta manera nuevos significados que se prestan al uso estilístico.

Palabras clave: perífrasis verbal, temporalidad, aspectualidad, modalidad, futuridad, ir a + infinitivo 